\title{
Heat, mortality, and level of urbanization: measuring vulnerability across Ohio, USA
}

\author{
Scott C. Sheridan*, Timothy J. Dolney \\ Department of Geography, Kent State University, Kent, Ohio 44242, USA
}

\begin{abstract}
Few studies have examined heat vulnerability on a sub-metropolitan area level. This paper presents an analysis of heat vulnerability across Ohio (USA) on a county level. Each county is classified as 'urban', 'suburban', or 'rural'. Four different criteria defining what is meteorologically 'oppressive' are evaluated individually. Each of these criteria is associated with an increase in mortality of several percent statewide. Absolute increases in mortality are greatest across urban counties, as expected. When these values are evaluated as a percentage increase in mortality, rural and suburban counties actually show a greater response. The differences among the 3 groups are not statistically significant. This research thus suggests that merely being an urban resident does not make one more vulnerable to heat.
\end{abstract}

KEY WORDS: Heat vulnerability · Human mortality - Synoptic climatology · Atmospheric hazard · Suburban $\cdot$ Urban $\cdot$ Rural $\cdot$ Ohio (USA)

\section{INTRODUCTION}

In contrast to most other atmospheric hazards, the impacts of heat on human health have been largely understated over time, despite the fact that heat is a deadlier phenomenon than all other atmospheric phenomena combined. From 1979 to 1999, the deaths of 8015 Americans were associated with excessive heat exposure (Center for Disease Control 2002). These are only the direct casualties, however, as there is no consensus on what constitutes a 'heat-related death', and death certificates often do not identify when heat has acted as a catalyst in exacerbating pre-existing cardiovascular, respiratory, and other problems (e.g. Ellis \& Nelson 1978). When these deaths are included, the actual toll is far higher. Indeed, during the hot summer of 1980 alone, across the US some 10000 deaths may have been associated with the oppressive heat (National Climatic Data Center 2002).

Particularly since 1995, when graphic images of hundreds of Chicagoans perishing in a July heat wave appeared in the media, interest in better protecting the public from the effects of oppressive heat has increased significantly. Some previous research has focused on the development of heat watch/warning systems (e.g. Kalkstein et al. 1996, Sheridan \& Kalkstein 1998), both to improve the forecasting of oppressive heat and the mitigation of its effects. Part of any attempt at mitigating the effects of heat involves the identification of the most vulnerable segments of the population. Much effort has focused upon parameters that are national or regional in scale to better understand the large-scale spatial variability in human vulnerability. The most important factor in explaining this variability is regional acclimatization (e.g. Kalkstein \& Davis 1989, Kalkstein \& Greene 1997, Davis et al. 2002). For example, Kalkstein \& Davis (1989) examined summer mortality in 48 US metropolitan areas for threshold apparent temperatures (defined in Section 2.2), above which total mortality is observed to rise. Their results show regional variability; for example, the threshold apparent temperature is $34^{\circ} \mathrm{C}$ in Chicago and $43^{\circ} \mathrm{C}$ in Phoenix, testament to different climates and the local populations' acclimatization to them. These studies suggest that the strongest response to heat in terms of human mortality is in the middle latitudes, i.e. in locations where summer conditions feature irregularly occurring but intense heat 
waves, which fall outside the acclimatized range of the local population (e.g. Kalkstein \& Davis 1989). In extreme cases, mortality can increase $100 \%$ above average levels (Ellis 1972).

Much less research has examined human vulnerability on a sub-metropolitan area scale. Initial inquiries suggest that several factors, including age, income level, and level of social isolation, may be important (Smoyer 1998, McGeehin \& Mirabelli 2001). Racial responses appear to vary within individual heat waves (Whitman et al. 1997) and perhaps on a regional level (Kalkstein \& Davis 1989), though no universal pattern has been noted. Mortality increases among those $65 \mathrm{yr}$ and older are much more significant than those of younger persons. Mortality increases of those under $65 \mathrm{yr}$ of age are often not statistically significant (Greenberg et al. 1983, Kilbourne 1997).

Nearly all studies that have focused upon heatrelated mortality and morbidity have concentrated upon urban areas. Much of the rationale lies in the availability of data: large cities or metropolitan areas often have a greater availability of meteorological data, both in terms of period of record and the number of meteorological variables. Further, these locations contain far greater sample sizes of human-mortality totals, or any other health response. Nevertheless, much of the existing literature also suggests that urban residents are more significantly affected than rural residents by oppressive heat (e.g. McGeehin \& Mirabelli 2001). Some modeling studies of the impacts of future climate change ignore the possibility that rural residents may be vulnerable as well (Tol 2002). The urban heat island, building types, greater social isolation, and higher cost of living are all often cited as the culprits for this differential. Events such as the heat wave of July 1995 have supported this notion.

This research presents an initial analysis into heatrelated vulnerability across various 'levels of urbanization' (i.e. rural, suburban, and urban) by examining county-level heat-related mortality rates across the state of Ohio, USA. Four different thresholds of what is meteorologically 'oppressive' are evaluated in relation to each county's mortality response. Results are analyzed in terms of both absolute increase in deaths and percentage increase in mortality, relative to the baseline.

\section{DATA AND METHODS}

\subsection{Mortality data}

Mortality data were obtained from the National Center for Health Statistics (NCHS) for the state of Ohio for the period 1975-1998. For each death, numerous para- meters are recorded, including date, county, primary and underlying causes of death, as well as a host of demographic information (e.g. age, race, sex). However, only 'total mortality' values are considered in this study. Stratifications for race, sex, or cause of death are not made. An initial inquiry in this work did not uncover any consistent differences among the races or sexes. As evidence has shown, mortality rates of numerous causes increase during oppressively hot conditions (Kalkstein \& Davis 1989, Kalkstein 1991); therefore no stratification by cause of death is necessary either. Furthermore, due to the small totals of deaths in rural areas, stratification of this variable would unduly complicate analysis.

As this study examines heat-related mortality, only the period from 15 May to 30 September (hereafter 'summer') is analyzed for each available year. Many of Ohio's counties have undergone significant demographic transitions during the $24 \mathrm{yr}$ period of record. Analyzing mean total mortality without standardization would yield biased results if certain meteorological conditions tended to occur more frequently early or late in the period of analysis. Thus, mean daily 'anomalous' mortality (either below or above an expected value) is analyzed instead. To obtain anomalous mortality for a particular day, a 'baseline' or 'normal' value of mortality is subtracted from that day's total mortality. The normal value of mortality is calculated by the annual summer mean mortality for the particular county. For example, anomalous mortality in Cuyahoga County for any day in the summer of 1982 is calculated by subtracting the mean daily mortality for the summer of 1982 from the actual total on each day of interest.

There is a clear seasonal cycle in mortality in Ohio if the entire year is considered, with winter mortality 10 to $15 \%$ greater than summer mortality. However, within the time frame of 15 May to 30 September, there is no statistically significant variability due to season. Thus, no intraseasonal adjustment is made in this research.

\subsection{Meteorological data}

Meteorological data were provided by the National Climatic Data Center, and include hourly observations for the 9 locations depicted in Fig. 1. This research utilizes 2 methods of evaluation of this meteorological information. First, a synoptic climatological approach is employed, in particular, the Spatial Synoptic Classification (SSC) (Sheridan 2002; more information on the SSC is available at http://sheridan.geog.kent.edu/sSc. html). The SSC classifies each day at a particular location into 1 of 7 weather types, or a transitional situa- 


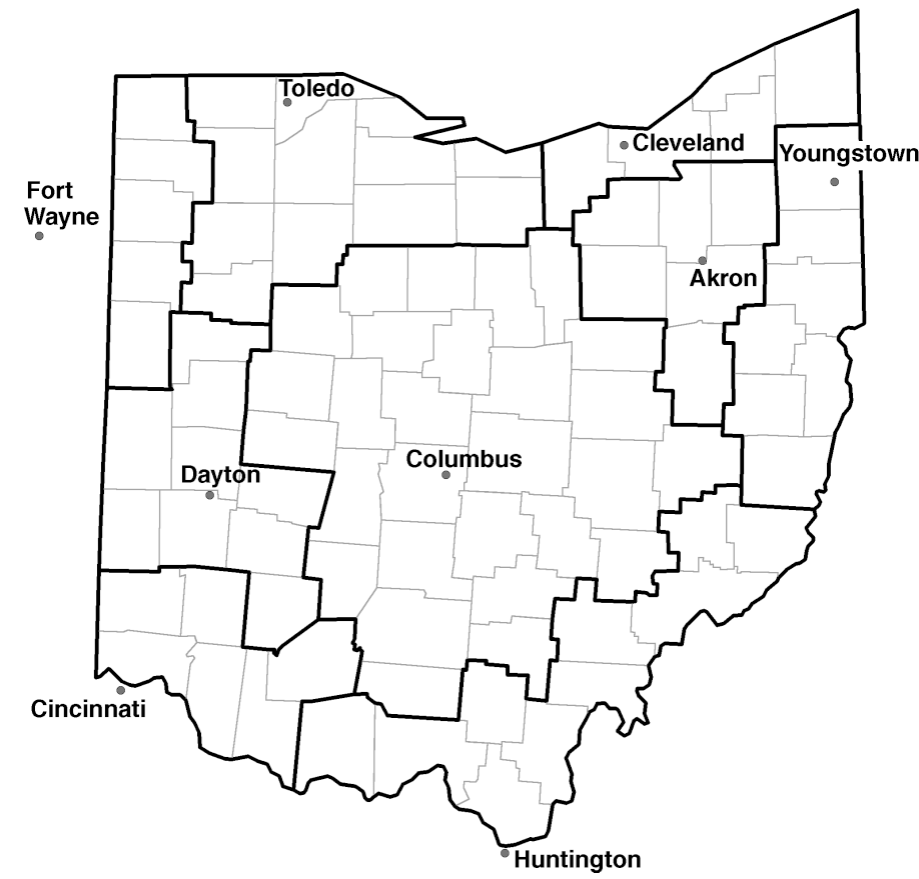

Fig. 1. First-order weather stations (denoted by dots) and the counties associated with them (separated by dark outline)

tion. For the purposes of this research, only 2 weather types are examined, both of which have been previously found to be 'oppressive':

- Dry tropical (DT) - hot and dry conditions with high insolation levels, and

- Moist tropical plus (MT+) - very warm and humid, with high overnight temperatures.

These 2 weather types are among the least commonly occurring in Ohio, together accounting for approximately $7 \%$ of summer days. Conditions associated with these weather types are listed in Table 1.

Second, the relationship between mortality and apparent temperature thresholds are analyzed. The apparent temperature (Steadman 1979) is a single vari- able calculated from temperature, humidity, and wind speed, and it is often considered superior to comparisons with either temperature or humidity alone (Kunkel et al. 1999). Mortality was compared to values of afternoon, overnight, and mean daily apparent temperature. As results were similar among the different measures, only afternoon (17:00 h EDT) apparent temperature results are presented here. Two thresholds are analyzed: $35^{\circ}$ and $38^{\circ} \mathrm{C}$. The $35^{\circ} \mathrm{C}$ threshold represents a common threshold above which mortality has been observed to rise in many of Ohio's counties in this research; however, it should be noted several counties have lower thresholds (as low as $29^{\circ} \mathrm{C}$ ) above which mortality statistically significantly rises. A threshold of $40^{\circ} \mathrm{C}$ was also considered, to correspond with the National Weather Service's official criterion for an excessive heat warning; yet too few days reached this criterion for the analysis to be meaningful, especially in northern and eastern Ohio.

\subsection{Comparisons}

Both the weather-type classification and apparent temperature values require meteorological data only available from 'first-order' stations, which limits us to incorporating only those stations shown in Fig. 1. These 9 stations therefore must be utilized for all of Ohio's 88 counties, requiring an 'association' of each county to 1 station. The process of determining this association incorporates both geographical and meteorological cohesion. Initial association was based on meteorological similarities. As long-term records of maximum and minimum temperature data are available at far more stations than those of any other parameter, they were used to compare meteorological similarity. The mean of the 30 yr (1971-2000) normal summer maximum and minimum temperatures for all weather stations within each county (also provided by

Table 1. Mean (SD) of 05:00 h $\left(T_{05}\right)$ and 17:00 h $\left(T_{17}\right)$ temperature $\left({ }^{\circ} \mathrm{C}\right), 17: 00 \mathrm{~h}$ dew point $\left(T_{\mathrm{d} 17},{ }^{\circ} \mathrm{C}\right)$, and daily cloud cover $(\mathrm{CC}$, tenths) in July for the 2 weather types analyzed for all first-order weather stations used in this research. All times are Eastern Daylight Time (EDT)

\begin{tabular}{|c|c|c|c|c|c|c|c|c|}
\hline \multirow[t]{2}{*}{ City } & \multicolumn{4}{|c|}{ _ Dry tropical _- } & \multicolumn{4}{|c|}{ - Moist tropical plus } \\
\hline & $T_{05}$ & $T_{17}$ & $T_{\mathrm{d} 17}$ & $\mathrm{CC}$ & $T_{05}$ & $T_{17}$ & $T_{\mathrm{d} 17}$ & $\mathrm{CC}$ \\
\hline Akron & $20(2)$ & $34(2)$ & $14(3)$ & $4.1(2.7)$ & $23(1)$ & $31(2)$ & $22(3)$ & $4.5(2.3)$ \\
\hline Cincinnati & $23(3)$ & $36(2)$ & $16(3)$ & $3.4(2.4)$ & $24(1)$ & $33(2)$ & $23(2)$ & $3.8(2.4)$ \\
\hline Cleveland & $20(2)$ & $33(2)$ & $16(4)$ & $3.7(2.8)$ & $23(2)$ & $31(2)$ & $22(4)$ & $4.4(2.4)$ \\
\hline Columbus & $21(3)$ & $35(2)$ & $15(3)$ & $3.7(2.3)$ & $24(2)$ & $33(2)$ & $22(3)$ & $3.9(2.1)$ \\
\hline Dayton & $23(3)$ & $35(2)$ & $17(2)$ & $2.6(2.1)$ & $24(1)$ & $34(2)$ & $23(3)$ & $3.6(2.4)$ \\
\hline Fort Wayne & $20(3)$ & $35(2)$ & $15(3)$ & $3.2(2.4)$ & $23(2)$ & $32(2)$ & $22(3)$ & $4.0(2.7)$ \\
\hline Huntington & $21(3)$ & $35(2)$ & $15(4)$ & $3.8(2.4)$ & $23(1)$ & $31(2)$ & $22(2)$ & $4.2(2.8)$ \\
\hline Toledo & $20(3)$ & $34(2)$ & $16(3)$ & $3.6(2.5)$ & $22(2)$ & $32(2)$ & $22(3)$ & $4.0(2.8)$ \\
\hline Youngstown & $18(3)$ & $33(3)$ & $14(3)$ & $3.8(2.9)$ & $22(1)$ & $31(2)$ & $21(2)$ & $4.5(2.6)$ \\
\hline
\end{tabular}


the National Climatic Data Center) were compared to those of the 9 first-order weather stations. Each county was then associated with the station that minimized meteorological differences. For counties with no stations, the nearest station in an adjacent county was used.

Due to the nature of this research, however, proximity to the weather station is important, and in several cases the county association was shifted to form the geographically contiguous areas depicted in Fig. 1. In cases where rearrangements were made, or one county was essentially equally similar to 2 first-order stations (means within $0.3^{\circ} \mathrm{C}$ ), the analyses performed in this research were run twice for the county, once for each station. For 38 counties a comparison was made: of the 152 tests performed (4 thresholds in 38 counties), in only 11 cases were the differences large enough to affect the statistical significance between the 2 runs. For the sake of clarity, only the associations shown in Fig. 1 are described.

\subsection{Urban, suburban, rural designations}

For this paper, an 'urban' county is defined as the most populated county in a metropolitan area (as defined by the US Census Bureau), if it contains a city with a population in excess of 75000 . There are 8 urban counties (Fig. 2). These counties comprise approximately $50 \%$ of Ohio's population over the period of interest, slightly decreasing through time. Of the $24 \mathrm{yr}$ statewide mean of 258 deaths $\mathrm{d}^{-1}, 150$ occurred in these 8 counties.

Suburban counties include all other counties classified by the US Census Bureau into a metropolitan area, aside from the 8 classified as urban. Thirty-one counties are thus 'suburban', comprising $32 \%$ of Ohio's population (with a slight increase over time), with a mean of 65 deaths $\mathrm{d}^{-1}$. The remaining 49 counties are not in a metropolitan area and are thus classified as 'rural'. These counties comprise the remaining 18\% of Ohio's population (steady over time), and average 43 deaths $\mathrm{d}^{-1}$.

In a number of rural counties, mean mortality is less than 1 death $\mathrm{d}^{-1}$. To make results from these counties more robust, in many cases adjacent rural counties have been amalgamated into county 'groups'. The choice in how to group the counties is by necessity subjective, due to the complex spatial distribution of rural counties around the metropolitan areas. The mean temperature values described in Section 2.3 are used here as well; all counties grouped together have mean summer maximum and minimum temperatures within $1^{\circ} \mathrm{C}$. Except where noted, 15 county groups in this work represent the 49 rural counties.

\subsection{Statistical significance testing}

Despite the clustering of rural counties into groups, in several cases the assumption of normality within the mortality data is inappropriate. As a result, in comparing the mortality totals observed on 'oppressive' days with those on 'non-oppressive' days, tests of statistical significance are undertaken using a randomization test (Fisher 1935). This test involves resampling the standardized mortality data set 10000 times for each measure of 'oppressive heat' for each county or county group. The level of significance is then determined by the percentage of these 10000 random samples for which the mean mortality increase exceeds that of the observed sample.

For example, for Cuyahoga County, there are 198 days in the $24 \mathrm{yr}$ period of record with an afternoon apparent temperature of at least $35^{\circ} \mathrm{C}$. On these days, the mean anomalous mortality is +2.2 deaths. Ten thousand random permutations of 198 days (with no regard to weather conditions) are selected from the period of record. To be significant at a level of significance of 0.05 , in fewer than 500 of the 10000 random samples would a mean anomalous mortality of at least

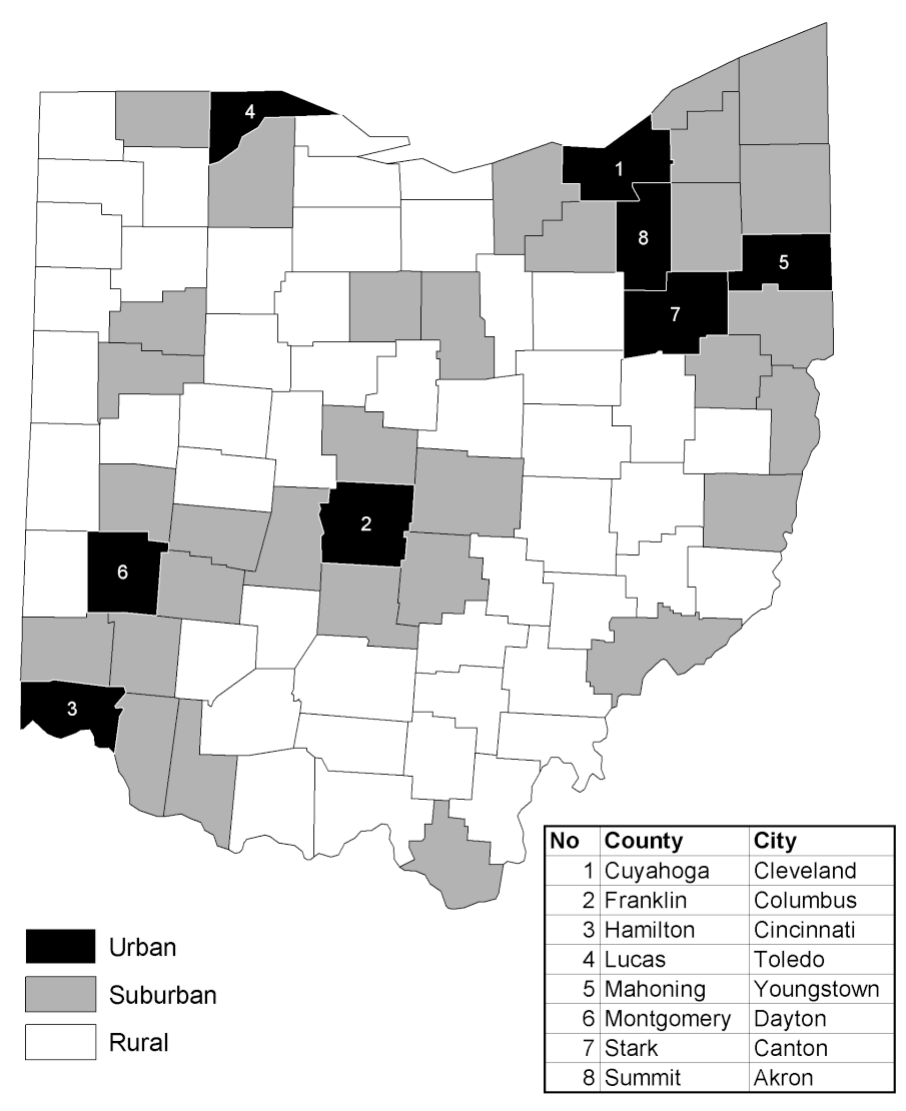

Fig. 2. Urbanization level of each county. Principal cities are listed 
Table 2. Mean frequency of occurrence and percentage increase in mortality relative to normal, using a 0 and $1 \mathrm{~d}$ lag, for the 4 meteorological criteria. The $1 \mathrm{~d}$ lag results are split into 2 groups, dependent upon whether the subsequent day also met the criteria. All increases are statistically significant at $\mathrm{p}<0.05$. DT: dry tropical; MT+: moist tropical plus; AT: apparent temperature

\begin{tabular}{|c|c|c|c|c|c|}
\hline \multirow{3}{*}{ Criterion } & \multirow{3}{*}{ 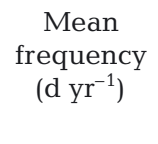 } & \multirow{3}{*}{$0 \mathrm{~d}$ lag } & \multicolumn{3}{|c|}{ - Percentage increase in mortality } \\
\hline & & & & $1 \mathrm{~d} \operatorname{lag}$ & \\
\hline & & & $\begin{array}{l}\text { All oppressive } \\
\text { days }\end{array}$ & $\begin{array}{l}\text { Next day is } \\
\text { also oppressive }\end{array}$ & $\begin{array}{l}\text { Next day is } \\
\text { not oppressive }\end{array}$ \\
\hline DT & 3.2 & 4.8 & 4.5 & 7.6 & 3.1 \\
\hline $\mathrm{MT}+$ & 6.6 & 5.8 & 4.8 & 7.5 & 4.2 \\
\hline $35^{\circ} \mathrm{C} \mathrm{AT}$ & 15.2 & 4.1 & 3.8 & 5.5 & 3.4 \\
\hline $38^{\circ} \mathrm{C} \mathrm{AT}$ & 4.0 & 7.1 & 7.3 & 14.3 & 6.8 \\
\hline
\end{tabular}

+2.2 be observed. This randomization test is considered as powerful as the parametric, 2-sample difference of means test, when the number of randomizations is sufficiently large (Fortin et al. 2002).

\section{RESULTS}

\subsection{Comparison of $0 \mathrm{~d}$ and $1 \mathrm{~d}$ lag}

Heat-related mortality is much more acute than coldrelated mortality (Kalkstein \& Valimont 1987, National Assessment Synthesis Team 2000); thus, any lag time analyzed is generally short. In many studies, correlations have been made between weather conditions and mortality with no lag time; in others, usually a $1 \mathrm{~d}$ lag is incorporated (e.g. Davis et al. 2002, Oechsli \& Buechley 1970). Both have been analyzed in this research, and the statewide results are depicted in Table 2 for each of the 4 thresholds examined. All four are associated with a mortality increase of several percent above normal levels with both $0 \mathrm{~d}$ and $1 \mathrm{~d}$ lags. There are no statistically significant correlations with lags beyond $1 \mathrm{~d}$, and no statistically significant differences among the different levels of urbanization. When the $1 \mathrm{~d}$ lag is split into cases when the following day was oppressive and when it was not oppressive, it is clear that the bulk of the $1 \mathrm{~d}$ lag heat response is caused by cases during which the following day was also oppressive. Thus, except where noted, results with the $0 \mathrm{~d}$ lag are presented here, as the mortality response is generally greater.

\subsection{Weather types: dry tropical and moist tropical plus}

For both of the weather types examined, statistically significant increases $(p<0.001)$ in mortality are noted statewide. DT is associated with a mean of 12.5 deaths above the baseline on the day of occurrence. DT occurs on average 2 times per summer in northeastern Ohio, increasing to nearly 5 occurrences in the western part of the state. Around half of the excess deaths observed occur in the 8 urban counties; Hamilton County and Cuyahoga County show the largest mean response on DT days, with 1.7 and 1.3 additional deaths, respectively (Fig. 3).

When anomalous mortality is analyzed as a percentage relative to normal, however, a different pattern emerges (Fig. 4). Most urban counties show similar increases, averaging $3.4 \%$ statewide; all urban counties except for Mahoning are associated with some increase. Among the suburban counties and rural county groups, as a result of the lower baseline mortality values, percentage responses are much more variable. Overall, however, the increases are greater, aver-

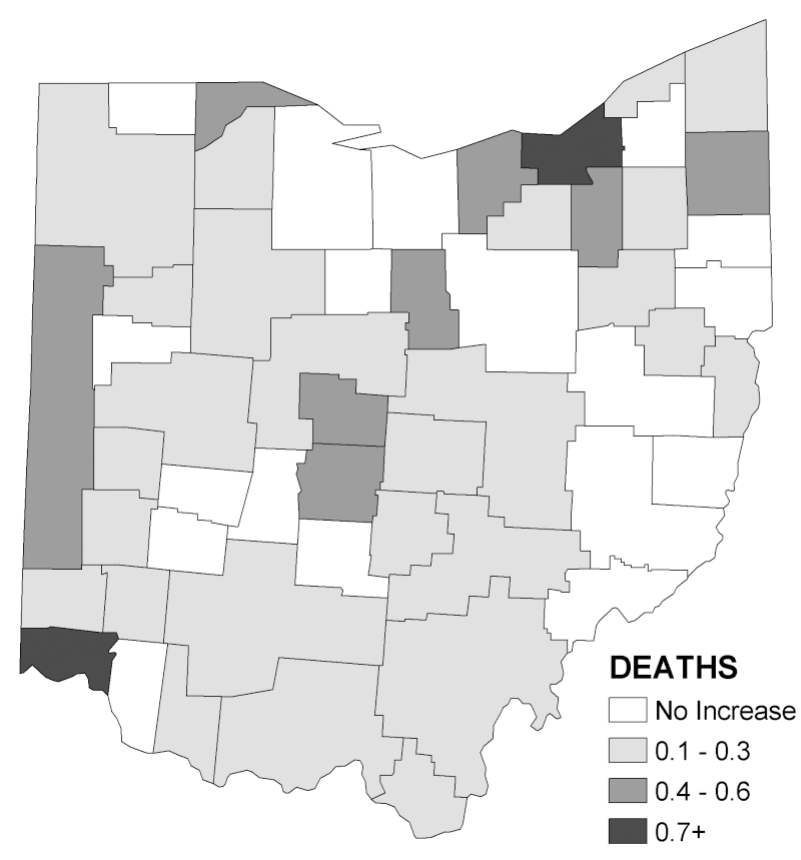

Fig. 3. Mean excess mortality response, in absolute number of deaths, on dry tropical (DT) days. Note that rural counties are depicted as county groups 


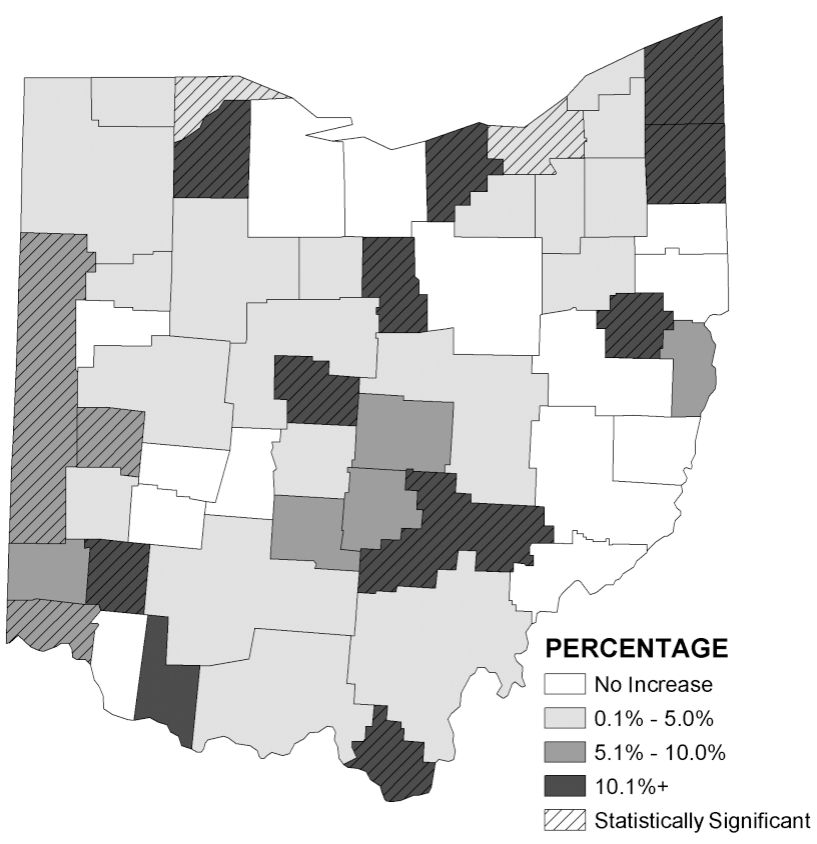

Fig. 4. Mean excess mortality response, in percent above normal, on DT days. Statistically significant increases $(p<0.05)$ are shown

aging $5.9 \%$ in the rural counties and $7.4 \%$ in suburban counties (Table 3). Around two-thirds of suburban counties and rural county groups are associated with an increase in mortality on DT days, although relatively few are statistically significant due to the lower mortality totals. Some rural county groups are associated with increases in excess of $30 \%$.

$\mathrm{MT}+$ is somewhat more common across Ohio, with mean frequencies ranging from 4 occurrences per summer across northeastern Ohio to 10 occurrences in the southwestern part of the state. A slightly stronger mortality response is noted on MT+ days, with a mean increase of 15.0 deaths statewide. Once again, the urban counties are associated with approximately half of the excess mortality; the highest absolute increases include Cuyahoga County, 3.3 deaths, and Hamilton County, 1.3 deaths. As a percentage (Fig. 5), overall rural and suburban counties are again more significantly affected than the urban counties with MT+. Overall on MT+ days, 42 of 46 suburban counties and rural county groups associated with some increase in mortality.

Spatially, there does not appear to be any significant patterns across the state. A greater number of statistically significant counties and county groups appears with MT+ (26) than DT (15). There is a slight differential in northeastern Ohio, the most industrialized area of the state, with results suggesting a stronger mortality response and less variability among counties with MT+ compared with DT. It should be noted that this area of the state is associated with the lowest temperatures during DT days, with significant nighttime cooling (Table 1).

\subsection{Apparent temperature thresholds}

While the weather types account for local variability within Ohio's climate (Table 1), the apparent-temperature thresholds are fixed levels statewide. Thus, in comparison with the weather types, there is a much larger variability in these thresholds' frequency of occurrence. The $35^{\circ} \mathrm{C}$ threshold is exceeded 6 times as often over the period of study in Dayton (30 occurrences $\mathrm{yr}^{-1}$ ) as Youngstown (5). The $38^{\circ} \mathrm{C}$ threshold is even more skewed: over 10 occurrences $\mathrm{yr}^{-1}$ on average were recorded in Dayton, and less than 1 in Youngstown.

With an apparent temperature in excess of $35^{\circ} \mathrm{C}$, on average 10.5 additional deaths occur statewide. Once again, approximately half of these deaths are in the urban counties. In this case, a spatial pattern is more

Table 3. Mean mortality response by level of urbanization ( $0 \mathrm{~d}$ lag) for the 4 oppressive criteria. Response is evaluated in anomalous deaths, percentage relative to baseline, and rate per 1000000 population. Statistically significant refers to the number of individual counties or county groups that are associated with mortality increases significant at $\mathrm{p}<0.05$

\begin{tabular}{|lrrrr|}
\hline & DT & MT + & AT $35^{\circ} \mathrm{C}$ & AT 38 ${ }^{\circ} \mathrm{C}$ \\
\hline Rural counties (15 groups) & & & & \\
Increase in deaths & 2.5 & 2.7 & 2.3 & 3.4 \\
Percentage increase & 5.9 & 6.2 & 5.4 & 8.1 \\
Rate per 1 000 000 & 1.2 & 1.3 & 1.1 & 1.7 \\
County groups with increases & 10 & 13 & 13 & 11 \\
Statistically significant & 2 & 7 & 9 & 6 \\
Suburban counties (31 counties) & & & & \\
Increase in deaths & 4.8 & 4.9 & 3.3 & 4.7 \\
Percentage increase & 7.4 & 7.6 & 5.1 & 7.1 \\
Rate per 1 000 000 & 1.4 & 1.5 & 1.0 & 1.4 \\
Counties with increases & 23 & 29 & 26 & 21 \\
Statistically significant & 10 & 14 & 12 & 11 \\
Urban counties (8 counties) & & & & \\
Increase in deaths & 5.2 & 7.4 & 5.0 & 10.3 \\
Percentage increase & 3.4 & 4.9 & 3.4 & 6.8 \\
Rate per 1 000 000 & 1.0 & 1.4 & 0.9 & 1.9 \\
Counties with increases & 7 & 7 & 6 & 7 \\
Statistically significant & 3 & 5 & 6 & 4 \\
\hline
\end{tabular}




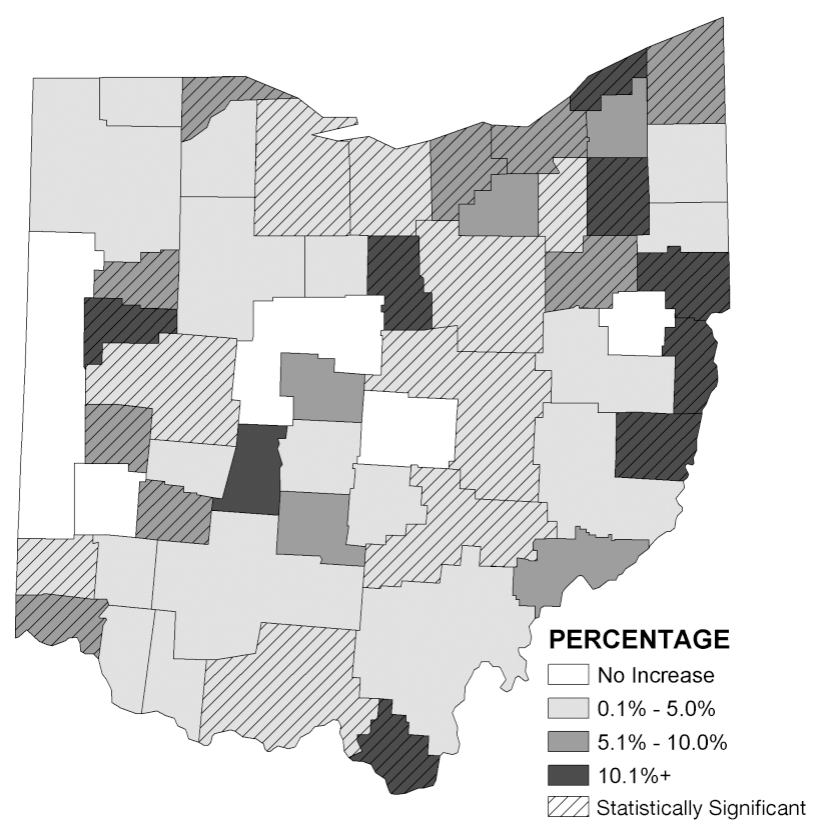

Fig. 5. Mean excess mortality response, in percent above normal, on MT+ days. Statistically significant increases $(p<0.05)$ are shown

apparent, as the 3 urban counties with the most significant increase are all in the north: Cuyahoga County averages 2.2 additional deaths, followed by Lucas and Stark. Hamilton County, at the southern end of the state, averages a statistically insignificant 0.3 deaths when all days at $35^{\circ} \mathrm{C}$ and above are considered.

Relative to the baseline, percent increases are once again greater in rural and suburban counties, with increases over $5 \%$. Urban counties collectively are associated with a $3.4 \%$ increase in mortality. While the pattern is not without exception, there is a tendency for more significant increases across the north of the state (Fig. 6) across suburban and rural areas as well, with rates particularly high in northeastern Ohio.

Examining the days solely above the $38^{\circ} \mathrm{C}$ threshold, the least-frequently occurring of the criteria, as well as the most oppressive days, the mean response is the greatest of all the criteria evaluated, with 18 deaths above the baseline on average. Here the most significant urban mortality increase is noted, with mortality $6.8 \%$ above normal levels. The urban counties also show the largest increase in terms of mortality rate of all criteria examined, with 1.9 additional deaths per 1000000 population on days with an apparent temperature of at least $38^{\circ} \mathrm{C}$. Spatially (Fig. 7), there is a more even balance across the state than with the $35^{\circ} \mathrm{C}$ threshold, with significant increases throughout. Many counties in the northeastern part of the state have large increases that are not statistically significant due to the small sample size.

\subsection{Variability across levels of urbanization}

In order to test whether there is any difference in mortality response among the different levels of urbanization, 2 additional tests were performed for each of the 4 thresholds examined above. First, we used a chi-square test of independence (Ott 1993) to assess whether there is a relationship between whether or not a county/county group has a statistically significant rise in mortality and that county/ county group's level of urbanization. For all 4 thresholds, results suggest (at $p<0.05$ ) that a county's level of urbanization is independent of whether or not it has a statistically significant increase in mortality. The nonparametric Kruskal-Wallis rank sum test (Rogerson 2001) ranks, for each of the 4 thresholds, the mean percentage increase in mortality for all county/county groups. The mean rank is then calculated for each of the 3 levels of urbanization. For all 4 thresholds, no statistically significant differences $(p<0.05)$ in these mean ranks are observed, suggesting that there is no relationship between the percentage increase in mortality and its level of urbanization.

\subsection{Total vulnerability}

Accounting for the results presented in Table 2, where the mean effects for 0 and $1 \mathrm{~d}$ lags were described, we have calculated the theoretical mean excess summer mortality on an annual basis for each

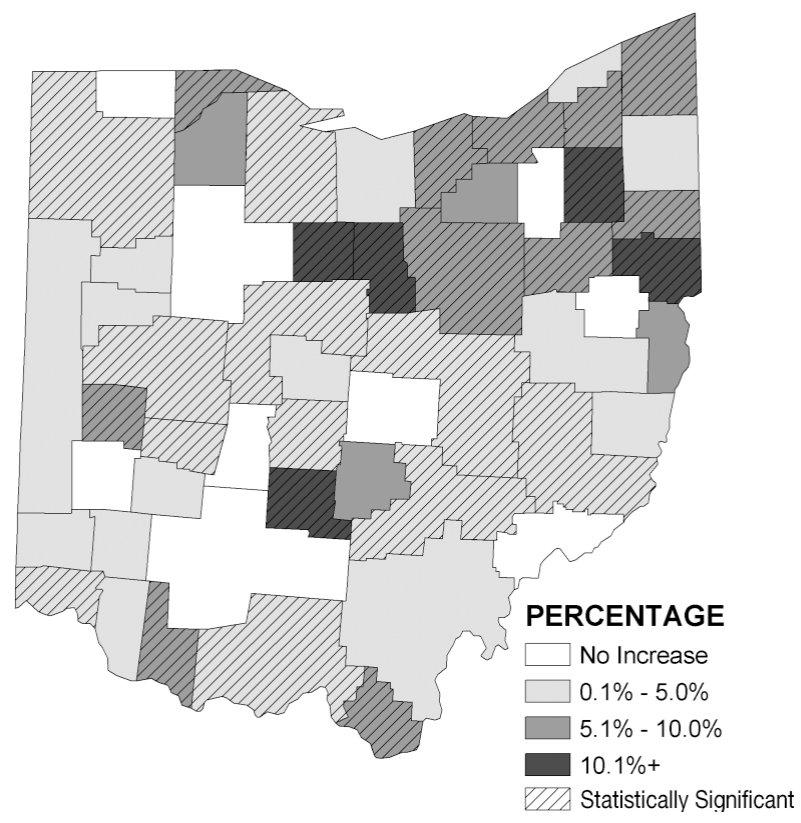

Fig. 6. Mean excess mortality response, in percentage above normal, when the afternoon apparent temperature exceeds $35^{\circ} \mathrm{C}$. Statistically significant increases $(\mathrm{p}<0.05)$ are shown 


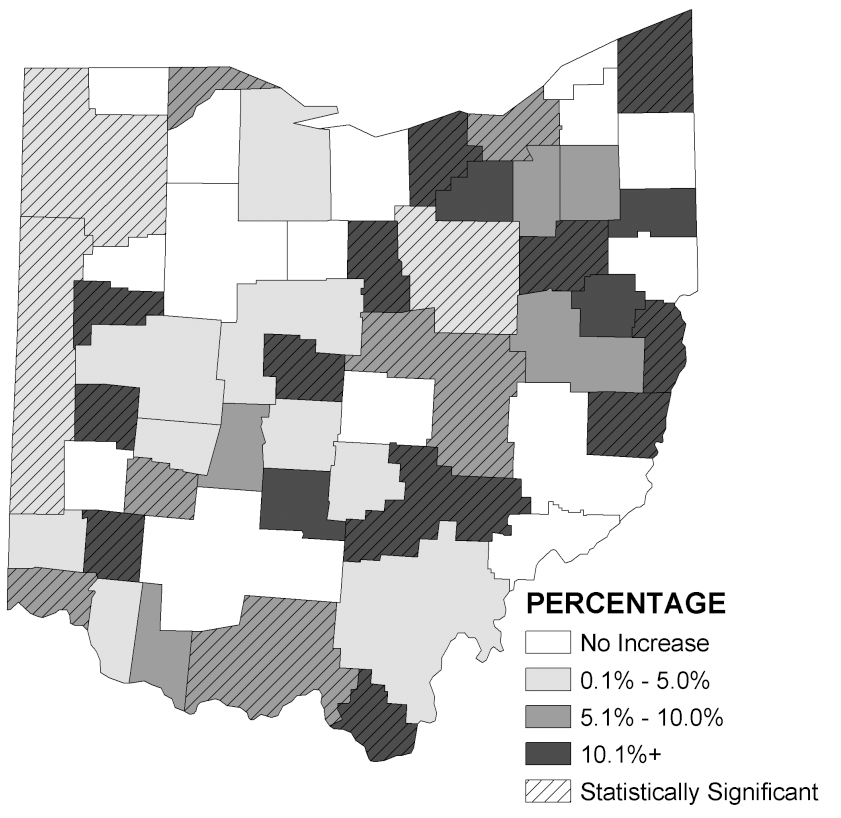

Fig. 7. Mean excess mortality response, in percentage above normal, when the afternoon apparent temperature exceeds $38^{\circ} \mathrm{C}$. Statistically significant increases $(\mathrm{p}<0.05)$ are shown

county in Ohio. Fig. 8 depicts the mortality response if one considers all DT and MT+ days to be 'oppressive'. Across the state of Ohio as a whole, approximately 249 extra deaths per summer are associated with the oppressive heat, according to the statistical relationships developed in this research. Cuyahoga County, the largest in the state, has a mean response of approximately 42 additional deaths per summer, followed by Lucas (20) and Hamilton (19). Overall, 114 deaths are in the urban counties, 80 in the suburban counties, and 55 in the rural counties. When analyzed as a rate, the pattern is reversed: the mortality rate is greatest in the rural counties (27 deaths per million population per year), followed by suburban (24), and urban (21).

\section{DISCUSSION}

The results presented above suggest that, while concentrations of excess mortality are largest in urban areas, relative to the population as a whole, urbanites appear to be no more vulnerable than rural residents to the effects of oppressive heat. Indeed, many of the tests performed suggest that rural and suburban residents are affected at a greater rate than urban residents, although the differences between levels of urbanization are not statistically significant.

Despite the lack of difference among the levels of urbanization when analyzed collectively, there is still much inter-county variability observed. Clearly, some urban areas are more affected than others. The older urban areas, particularly Cleveland (Cuyahoga County), Toledo (Lucas County), and Cincinnati (Hamilton County), are more significantly affected than Columbus (Franklin County), a newer city with fewer older houses. Dayton (Montgomery County) does not appear to be affected significantly using any of the 'oppressive' criteria. As one of Ohio's older cities, it is unclear why this is the case.

Among Ohio's rural counties, much more intercounty variability is observed. Much of this lies in the smaller baseline numbers. Despite the amalgamation into county groups, mean mortality totals are still lower than in urban and most suburban counties, and thus small mean fluctuations result in larger swings when converted to a percentage. Further, deaths obviously occur in discrete whole numbers, and so any one extra death in a rural area comprises a far greater percentage increase than one death in an urban area. Analyzed collectively at a statewide level, mean mortality among all rural counties is sufficiently large to depict a clear increase in mortality (Table 3). Analyzed in individual county groups, aside from the tendency for a greater number of statistically significant groups in the north with the $35^{\circ} \mathrm{C}$ threshold, no clear spatial patterns are evident.

If level of urbanization is not an important determinant of heat vulnerability, can any other parameters available on a county level be correlated with the variability observed? We have performed a preliminary

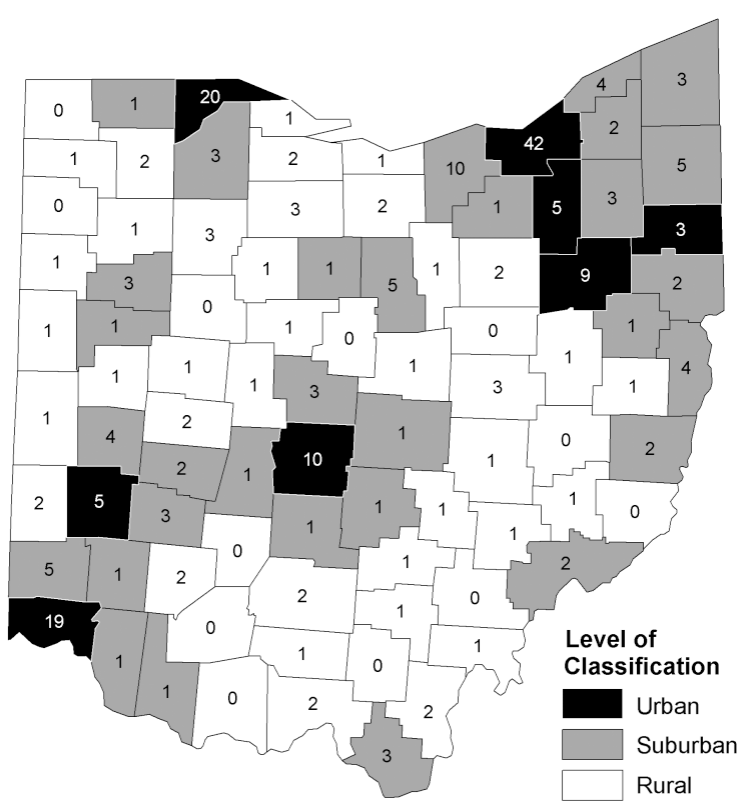

Fig. 8. Mean summer excess mortality (1975-1998) based on 'oppressive' weather-type threshold occurrences. Total represents the sum of mean excess mortality on DT and MT+ days multiplied by each weather type's mean frequency of occurrence 
analysis using county-level census data on several measures of poverty, cost of living, percentage of the population not in the workforce, and percentage of older-stock housing. None of these parameters proved to have any statistical correlation with any of the measures of mortality at the county level.

Among the 4 different criteria evaluated, some variability is observed in the results. The $38^{\circ} \mathrm{C}$ threshold logically is associated with a larger response than the $35^{\circ} \mathrm{C}$ threshold. The 2 weather types are in between. The weather-type approach, which accounts for the regional climate variability, does not show the regional variability present when using the $35^{\circ} \mathrm{C}$ threshold in particular. The spatial variability observed suggests that a $35^{\circ} \mathrm{C}$ apparent temperature is more oppressive to northern Ohio residents than those in the southwestern portion of the state. Thus, while the apparenttemperature threshold method may be useful for identifying the level at which conditions become 'oppressive', a weather-typing approach may be superior for evaluating population response to heat on days that the local population will consider to be 'oppressive', without having to account for regional variability in weather conditions.

Year-to-year variability is quite significant as well, but it has not been addressed in this article. Some research has shown that heat vulnerability has decreased in the US over recent decades, due perhaps to increased use of air-conditioning (Davis et al. 2002). Using the weather-type approach, some summers, including the cool summer of 1992 following the eruption of Mt. Pinatubo, were associated with virtually no excess mortality. At the other extreme, the hot summer of 1980 was associated with the greatest number of excess deaths in the state of Ohio over the period analyzed here. Still, this summer does not compare to the hot summers of the 1930s, particularly 1934 and 1936, when during heat waves, among a much smaller population, over 50 people directly perished per day across Ohio (Schmidlin \& Schmidlin 1996).

When analyzing the difference between rural and urban response to meteorological conditions, one must acknowledge the difference in ambient meteorological conditions between city and rural area. Most notably, cities are frequently warmer, particularly at night, though the magnitude depends on many factors, including synoptic situation (e.g. Sheridan et al. 2000). By utilizing weather data solely from airport locations within relatively urbanized areas, this study inherently accounts for microscale and local-scale differences in climate. For example, the mean mortality response to DT in urban Lucas County, which includes Toledo, and neighboring rural Sandusky County, are both based on the classification of DT days based at Toledo's airport. This would assumedly result in mean conditions in the rural county being somewhat less oppressive overall, particularly at night. In this light, it is particularly interesting that the urban/rural mortality differential is so low, as the urbanites it would be assumed may be subject to more oppressive outdoor conditions in all 4 thresholds examined.

The inclusion of more rural meteorological data could aid in further identifying how frequently different populations are subject to oppressive conditions. It may also be useful to include more detailed meteorological observations at all locations, including radiative balance models. However, any further refinement of meteorological data included in research would need to address the variability in conditions observed by individuals within a county, city, or even within a single building. Outdoor meteorological conditions correlate well with levels of heat stress, but cannot explain all of the variability experienced by the population: whether they are indoors are out, have access to air conditioning, live on the ground floor or top floor of an apartment, and so forth. Thus, while the relationship between ambient meteorological data and a largescale health response is significant, these weather data can only provide an estimate of the local conditions each individual is experiencing.

One last discussion point involves the interpretation of 'statistical significance'. Results are presented with statistical significance determined by the traditional threshold of $\mathrm{p}<0.05$. It should be noted, however, that the meteorological data are spatially autocorrelated, as they are only available for 9 locations, rather than for each county or county group. This spatial autocorrelation may inflate statistical significance in some cases. Due to the small sample size in many rural county groups, however, more stringent thresholds (e.g. $\mathrm{p}<0.01$ ) were not considered. In urban counties, of the results presented above, in only $12 \%$ of statistical tests would a result that is statistically significant at $\mathrm{p}<0.05$ not be significant at $\mathrm{p}<0.01$; correspondingly, in nearly $30 \%$ of rural county results would the statistical significance change. It should be noted that this is limited to individual county analysis only; when examined as aggregates of all counties of a particular level of urbanization (e.g. Table 2), all mortality increases remain statistically significant even at $\mathrm{p}<0.001$.

\section{CONCLUSIONS AND FUTURE DIRECTIONS}

While heat vulnerability has frequently been analyzed in the context of cities, results from this study suggest that rural and suburban mortality both increase during oppressively hot weather as well. In many cases, rural and suburban mortality increases at a greater rate than urban deaths, though the differ- 
ences between the different levels of urbanization as a whole are not statistically significant. These results are observed regardless of the criterion that is used to identify 'oppressive' days. Criteria that account for the regional variability in climate (e.g. weather types) show less spatial variability than those that do not (e.g. apparent temperature thresholds).

The reasons for the apparent lack of influence of level of urbanization upon one's vulnerability are still unclear. As the rural response to oppressive heat has rarely been examined, perhaps this undetected vulnerability has been present all along. It may also be that rural residents have less access to air conditioning, particularly those in the work force, considering the greater proportion of outdoor workers. Given the tendency for heat warning messages to be directed toward those in urban areas, it may be cultural as well: rural residents do not perceive themselves as being as vulnerable, or hear fewer warnings. The variability observed in this research, along with the census results presented above, stress that heat vulnerability is an individual-level variable, encompassing not only ambient outdoor conditions but also individual attempts at mitigating its effects, based on numerous social factors.

Finally, it is recognized that the categorization of one county as entirely 'urban', 'suburban', or 'rural' is an overgeneralization of the population that lives in these counties. Due to the lack of more precise classification in this statewide database, there is little recourse for re-classification in this type of analysis. Consequently, much more localized data are needed. Mortality data on a sub-county level may correlate better with demographic information available on a similar scale, as Smoyer (1998) has shown. Further microclimatological information, such as the relationship between outdoor meteorological observations and interior building temperatures, may help clarify levels of heat stress. Paramount to all of this, however, is information on personal action. As one's own environmental surroundings are critical in determining the amount of heat stress to which one must respond, more information on the population's perceptions of its own vulnerability and the course of action that individuals choose to take to protect themselves from the heat would significantly advance our understanding of a population's heat vulnerability.

Acknowledgements. The authors would like to thank The Research Council of Kent State University for helping support this research via a Summer Research Creativity Fellowship; L. S. Kalkstein, R. E. Davis, and K. E. Smoyer-Tomic for their assistance in the refinement of this research; W. P. Kent for acquiring several data sets; and M. D. Braham for assistance in editing the final document. We also express our appreciation to the 3 anonymous reviewers that aided considerably in improving this manuscript.

\section{LITERATURE CITED}

Center for Disease Control (2002) Heat-related deaths - four states, July-August 2001, and United States, 1979-1999. Morbidity Mortality Weekly Rep 51:567-570

Davis RE, Knappenberger PC, Novickoff WM, Michaels PJ (2002) Decadal changes in heat-related human mortality in the eastern United States. Clim Res 22:175-184

Ellis FP (1972) Mortality from heat illness and heat aggravated illness in the US. Environ Res 5:51-58

Ellis FP, Nelson F (1978) Mortality in the elderly in a heat wave in New York City, August, 1975. Environ Res 15:504-512

Fisher RA (1935) The design of experiments. Oliver \& Boyd, Edinburgh

Fortin MJ, Jacquez GM, Shipley B (2002) Computer-intensive methods. In: El-Shaarawi AH, Piegorsch WW (eds) Encyclopedia of environmetrics. John Wiley \& Sons, Chichester, p 399-402

Greenberg JH, Bromberg J, Reed CM, Gustafson TL, Beauschap RA (1983) The epidemiology of heat-related deaths, Texas, 1950, 1970-79, and 1980. Am J Public Health 73:805-807

Kalkstein LS (1991) A new approach to evaluate the impact of climate on human mortality. Environ Health Perspect 96: $145-150$

Kalkstein LS, Davis RE (1989) Weather and human mortality: an evaluation of demographic and interregional responses in the United States. Ann Assoc Am Geogr 79:44-64

Kalkstein LS, Greene JS (1997) An evaluation of climate/mortality relationships in large US cities and possible impacts of climate change. Environ Health Perspect 105:84-93

Kalkstein LS, Valimont KM (1987) Climate effects on human health: Potential effects of future climate changes on forest and vegetation, agriculture, water resources, and human health. EPA Science and Advisory Committee Monogr No. 25389, US Environmental Protection Agency, Washington, DC, p 122-152

Kalkstein LS, Jamason PE, Greene JS, Libby J, Robinson L (1996) The Philadelphia hot weather-health watch/warning system: development and application, summer 1995. Bull Amer Meteorol Soc 77:1519-1528

Kilbourne EM (1997) Heat waves and hot environments. In: Noji EK (ed) The public health consequences of disaster, Oxford University Press, Oxford, p 245-269

Kunkel KE, Pielke RA Jr, Changnon SA (1999) Temporal fluctuation in weather and climate extremes that cause economic and human health impacts: a review. Bull Am Meteorol Soc 80:1077-1098

McGeehin MA, Mirabelli M (2001) The potential impacts of climate variability and change on temperature-related morbidity and mortality in the United States. Environ Health Perspect 109:185-198

National Assessment Synthesis Team (2000) Overview: human health. In: Melillo JM, Janetos AC, Karl TR (Cochairs) Climate change impacts on the United States: The potential consequences of climate variability and change. The US Global Change Research Program, Washington, DC, p 102-107

National Climate Data Center (2002) Billion-dollar weather disasters, 1980-2002. National Climate Data Center, Boulder, CO. Available at http://www.ncdc.noaa.gov/ol/ reports/billionz.html (accessed 12 September 2002)

Oechsli FW, Buechley RW (1970) Excess mortality associated with three Los Angeles September hot spells. Environ Res 3:277-84

Ott RL (1993) An introduction to statistical methods and data analysis. Wadsworth Publishing Co, Belmont, CA 
Rogerson PA (2001) Statistical methods for geography. Sage Publications, London

Schmidlin TW, Schmidlin JA (1996) Thunder in the Heartland: a chronicle of outstanding weather events in Ohio. Kent State University Press, Kent, OH

Sheridan SC (2002) Redevelopment of a weather-type classification scheme for North America. Int J Climatol 22: 51-68

Sheridan SC, Kalkstein LS (1998) Health watch/warning systems in urban areas. World Resour Rev 10:375-383

Sheridan SC, Kalkstein LS, Scott JM (2000) An evaluation of the variability of air mass character between urban and rural areas. In: DeDear RJ, Kalma JD, Oke TR, Auliciems A (eds) Biometeorology and urban climatology at the turn

Editorial responsibility: Robert Davis,

Charlottesville, Virginia, USA of the millennium. World Meteorological Organization, Geneva, p 487-490

Smoyer KE (1998) Putting risk in its place: methodological considerations for investigating extreme event health risk. Soc Sci Med 47:1809-1824

Steadman RG (1979) The assessment of sultriness. Part I: a temperature-humidity index based on human physiology and clothing science. J Appl Meteorol 18:861-873

Tol RSJ (2002) Estimates of the damage costs of climate change. Part II, dynamic estimates. Environ Resour Econ 21:135-160

Whitman S, Good G, Donoghue ER (1997) Mortality in Chicago attributed to the July 1995 heat wave. Am J Public Health 87:1515-1518

Submitted: December 18, 2002; Accepted: May 29, 2003

Proofs received from author(s): August 8, 2003 